\title{
روبية هندية تحمل نقش للحرمين الثريفين
}

\section{د.محم محمود عبدالرازق}

أثنارى بالمكتب الفنى لرئيس قطاع المتاحف -ـوزارة السياحة و الآثار

\section{ملخص البحث :}

جاء تأسيس شركة الهند الثرقية نتيجة للتوسع التجاري الذي شهدته إنجلتر ا في النصف الأخير من

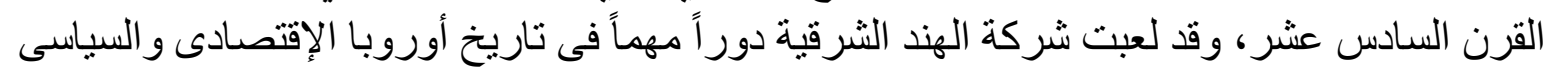

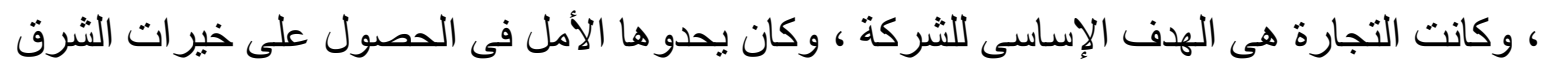
، وتوفير السلع الثرقية فى الأسواق الإنجليزية، ولم تقتصر إرباح الثركة من الهند فقط و إنما تعدتها

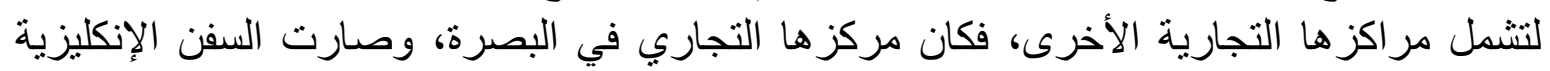

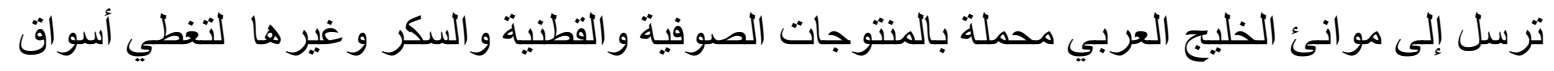
البلاد المحيطة بالخليج العربي، وأصبحت المناطق المطلة على الخليج العربي من الأسواق الرئيسية

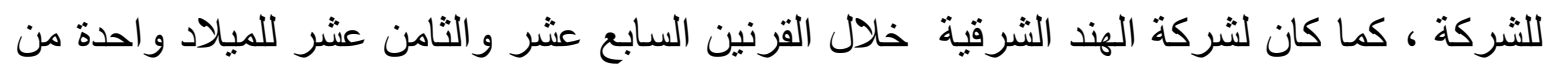

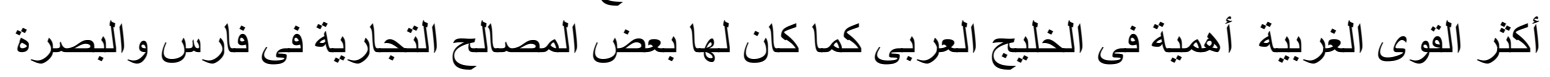

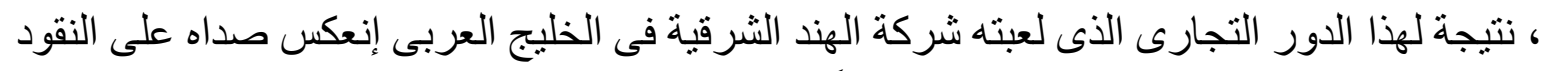

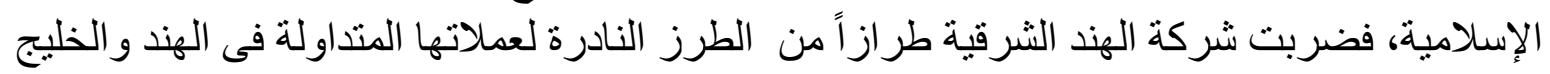
العربى الإسل

وسوف نتتاول فى هذا البحث - إن شاء الله - هذا الطراز النادر وما سجل عليه من كتابات وزخارف

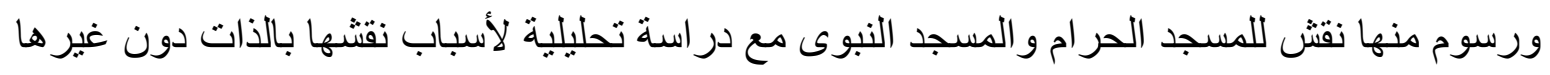
مع ربطها بالظروف و الأحداث التاريخية المعاصرة لها إضافة لإبراز أهميتها وقيمتها النقدية.

مقدمة : مقاف

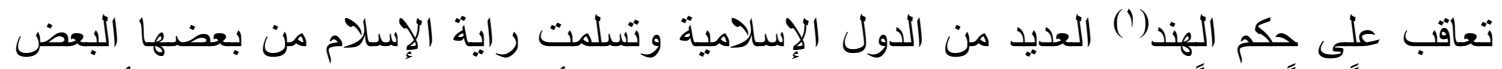

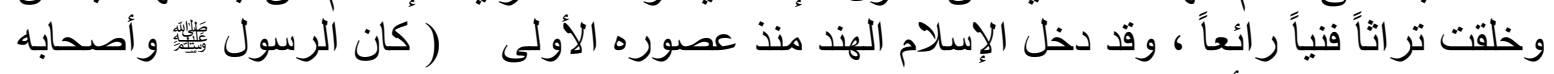

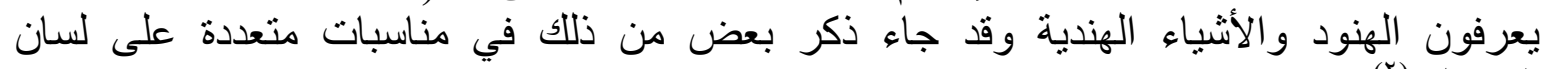

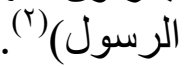
شهدت بلاد الهند أوج عظمتها و أقوى فتز ات تاريخها و أكثر عصور ها إزدهار اً فى عصر إمبر اطورية

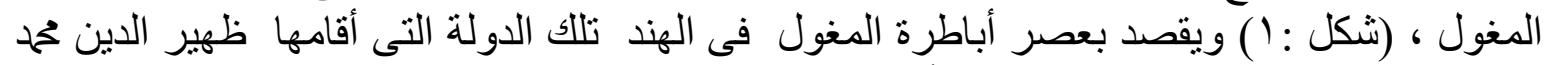

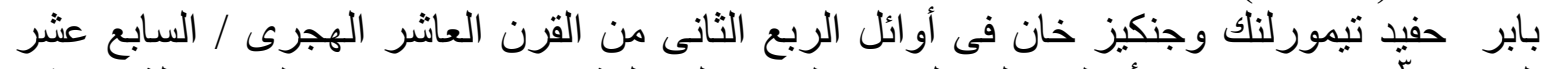

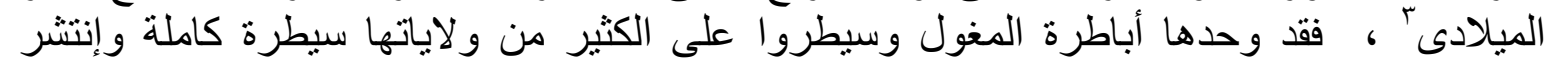

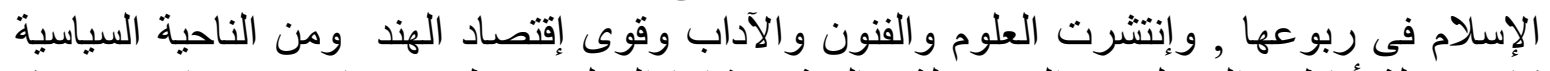

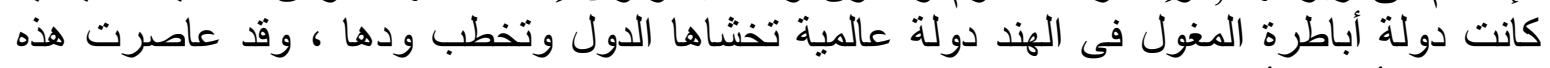

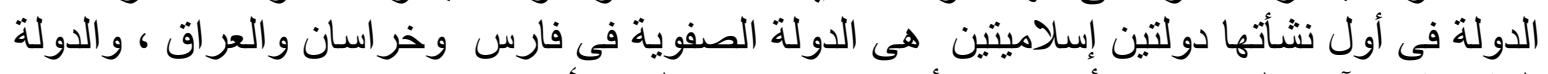

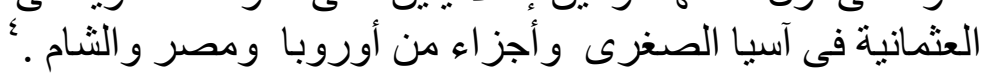


نقود شركة الهند الثرقية:ة

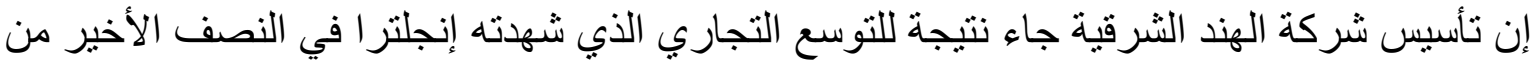

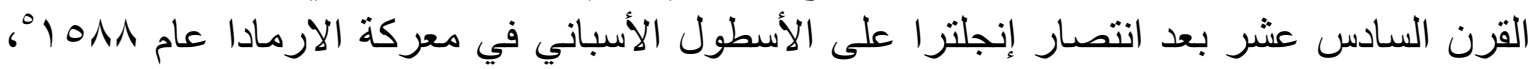

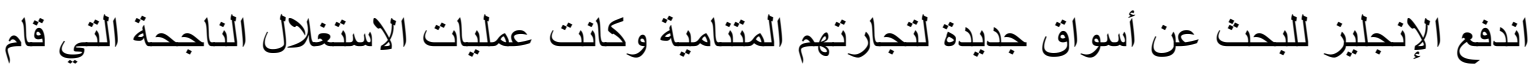

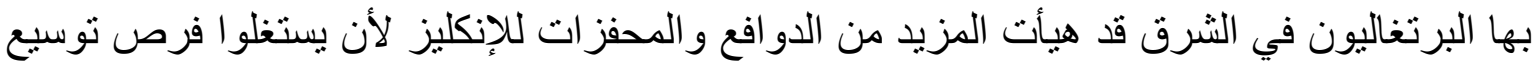

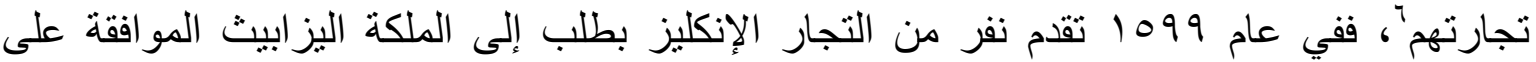

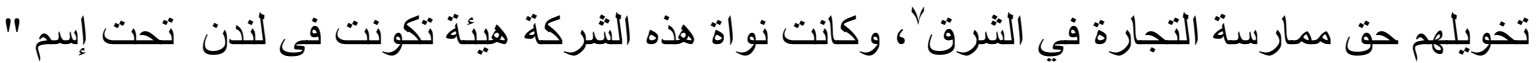
التجار المغامرين بهدف الإتجار في الثرقي" الثرق،

وقد صدر مرسوم ملكي بالموافقة عام . .17 عد بمثابة الحجر الأساسي لقيام شركة الهند الثرقية

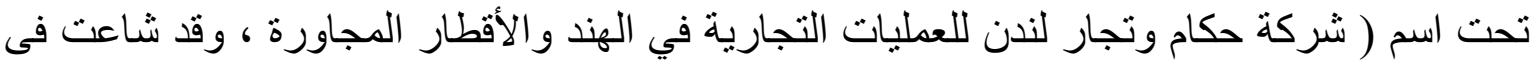

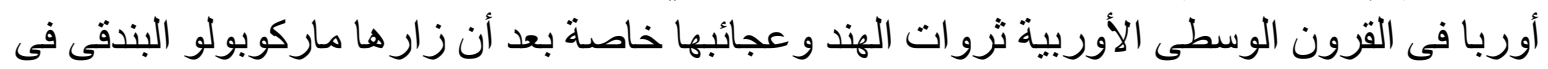

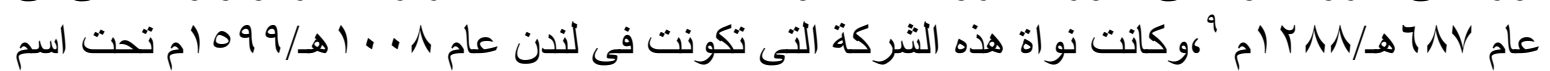

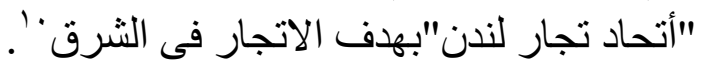

وقد لعبت شركة الهند الثرقية دور اً مهماً فى تاريخ أوروبا الإقتصادى و السياسى ، وكانت التجارة هى

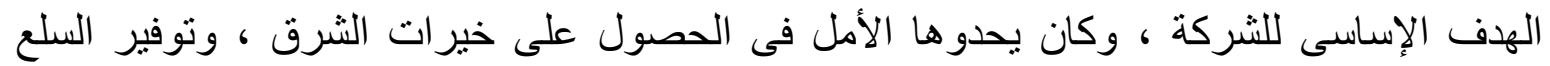

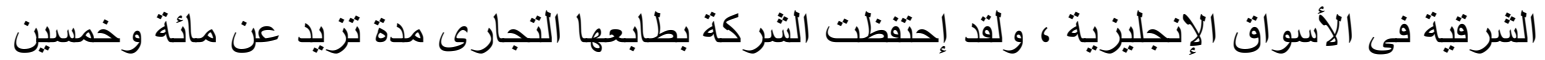

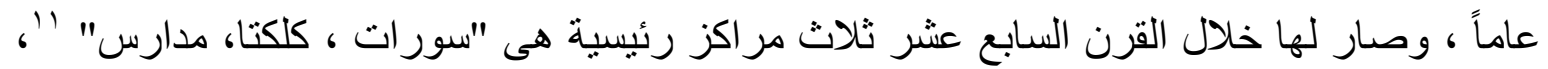

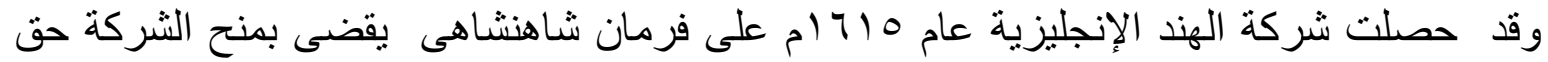

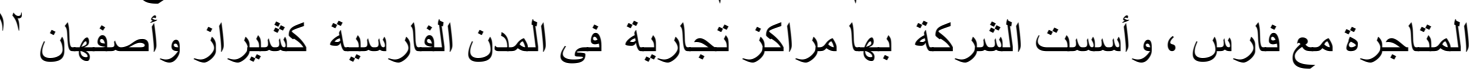

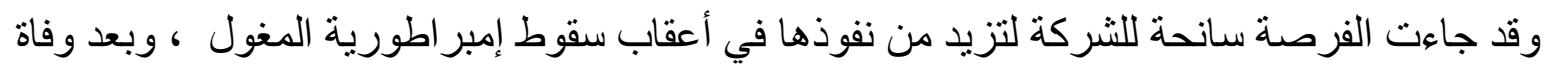

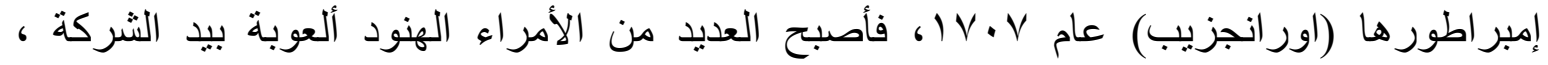

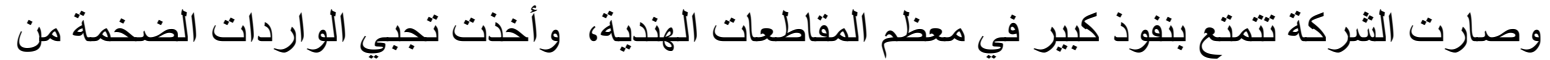

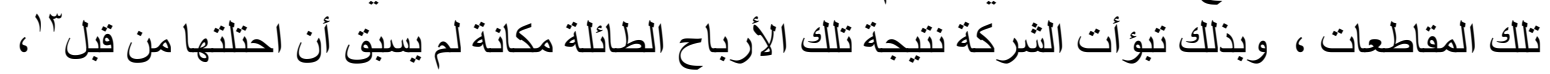

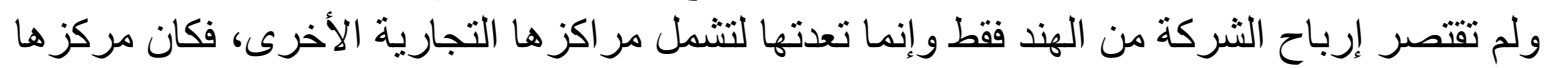

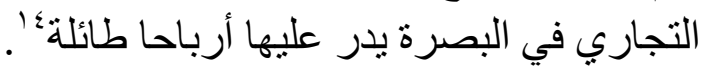

وقامت ثورة فى الهند نتيجة عدم رضا الهنود للإستغلال الإقتصادى للبلاد بو اسطة شركة الهند الثرقية

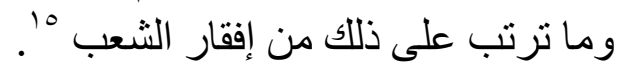

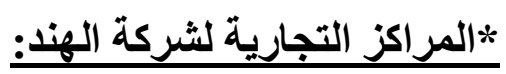

1-كلكتا:_تعتبر العاصمة التجارية لشركة الهند، فهى عاصمة الهند الإنجليزية لمقاطعة البنغال ، وفيها

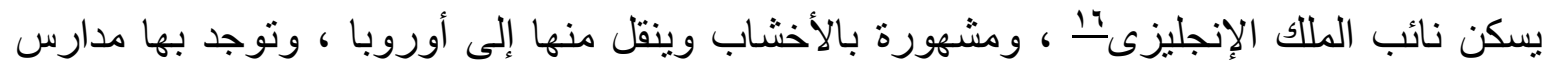

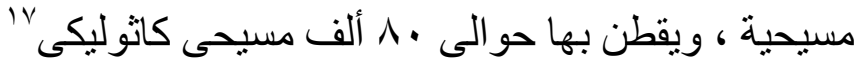

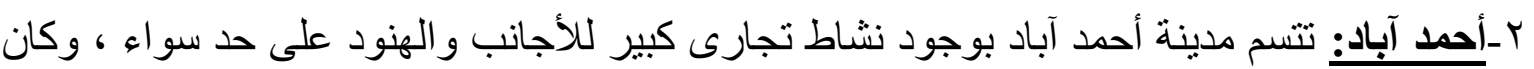

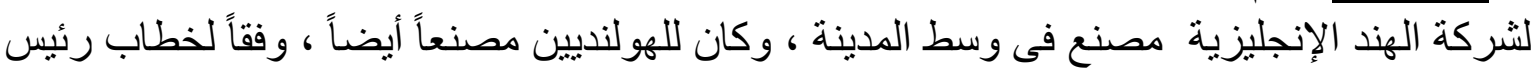


شركة الهند الثرقية ، فقد وصف أحمد آباد قائلاً "بأنها أهم المدن فى إقليم الكجر ات ، ومركز تجارى كبير

ץ-بومباى : من مر اكز التجارة الرئيسية ، حيث أنتجت مجموعة من السلع والمنتجات القطنية و التبغ وجوز الهند ، وكانت تصدر إلى أوروبا عبر شركة الهند الثرقية ، الثرية ، كما كانت من مر اكز التجارة الرئيسية لتصدير المنتجات الهندية إلى الجزيرة العربية 19 وقد ضربت شركة الهند الثرقية نقوداً بإسم حكام الأقاليم مثل حكام البنغال وبومباى ، ومن أمثلة

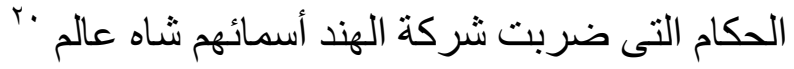
يحيط بكلاً من الوجه و الظهر دائرة خطية ، ونصوص الكتابات كالتالى : الوجه: رسم للمسجد الحر ام و المسجد النبوى"عبارة عن مئذنة عثمانية " ، الهلال و النجمة +797

\section{Ukl/Half/Anna/1818}

East india company
الظهر:

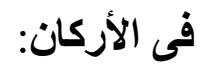

الوصف:-

يعبر هذا الطراز من الطرز النادرة ، حيث يضم مركز الوجه نقش للمسجد الحرام ب؟ متمثل فى الكعبة

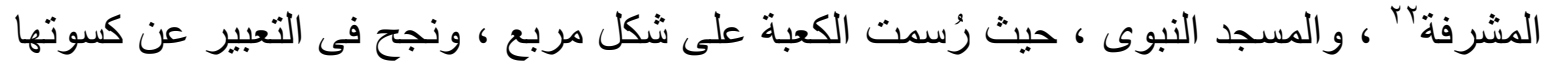

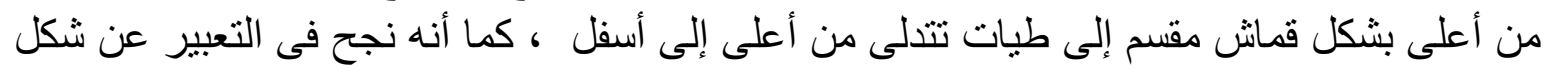

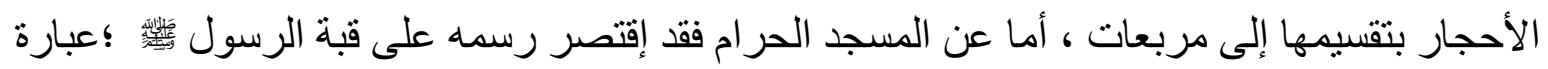

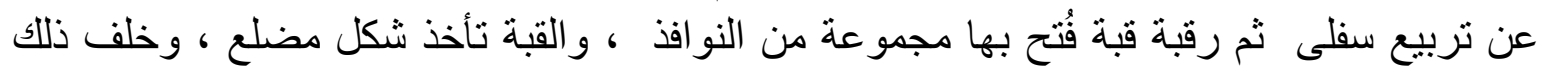

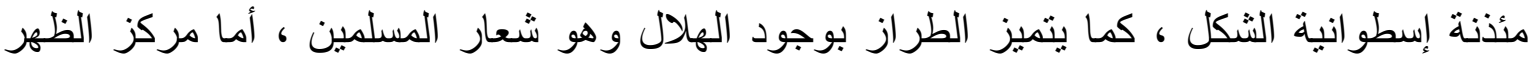

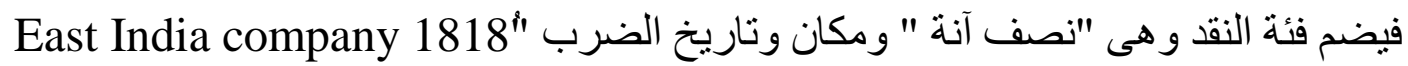
وربما من الأسباب التى دفعت شركة الهند الثرقية إلى نقش المسجد الحرام والكعبة المشرفة ربما يرجع ذلك إلى العلاقات التجارية بين شركة الهند وبلاد الخليج العربى آنذالك ؛ حيث توسعت التهن التجارة الإنجليزية مع فارس والعراق بَّ ، و الجدير بالذكر أن شركة الهند الثرقية كانت خلال القرنين السابع

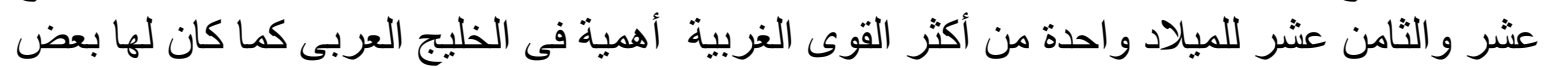

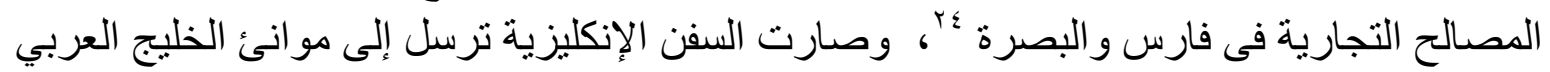
محملة بالمنتوجات الصوفية و القطنية و السكر و التوابل و غير ها لتغطي أسواق البلاد المحيطة بالخليج

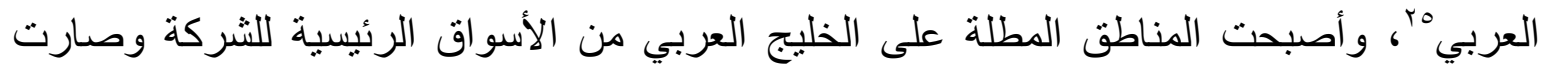

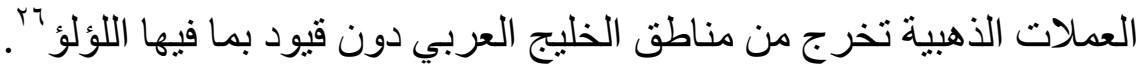
وربما من أهم الأسباب أيضاً هى مخاطبة ود المسلمين بنقش الأماكن المقدسة على عملاتها حتى

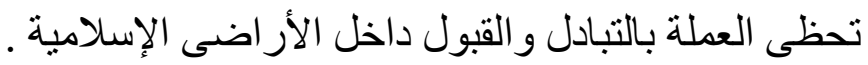
ينتمى إلى هذا الطر از نصف آنة فضية مؤرخة بسنة 1 | ( ا "تُنشر لأول مرة " 

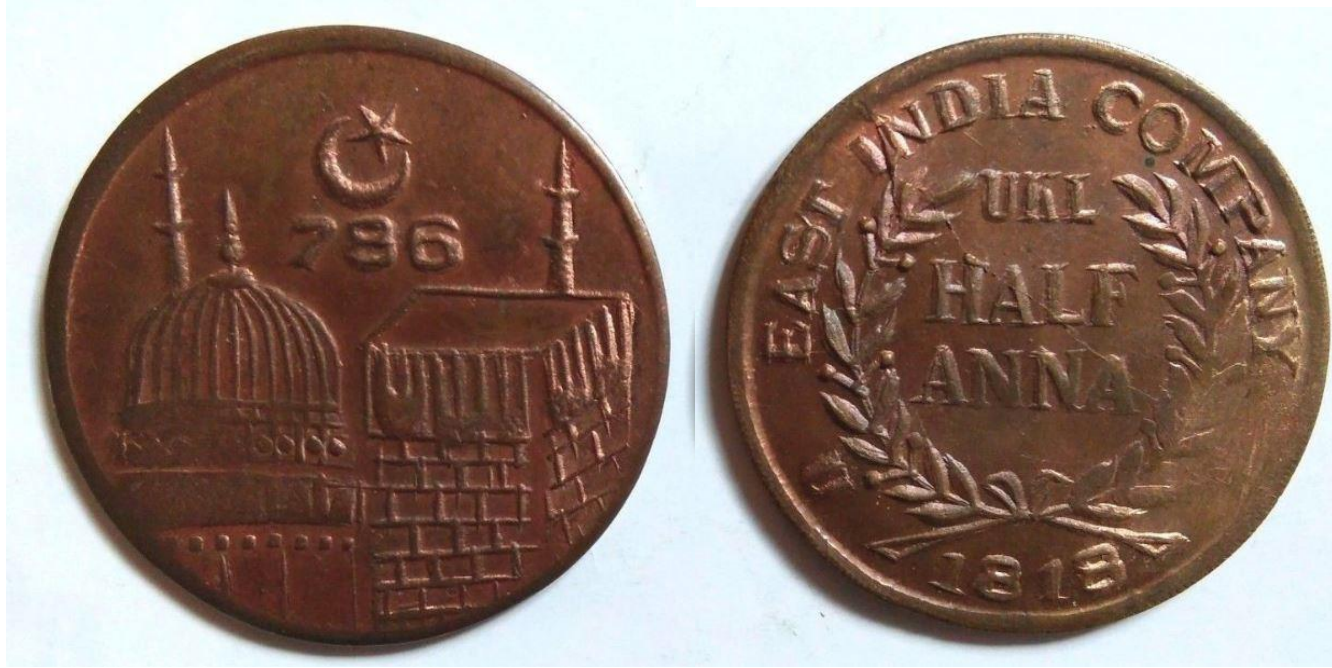

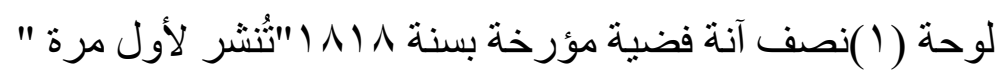

عن متحف نيو دلهى ، تحت رقم "68412A" 
'وتنتمد الهند اسمها من كلمة "سندهو "وهو الإسم الهندى لنهر "الأندوس" وهو نهر "السند" ومن هذه الكلمة أثتقت الأنت

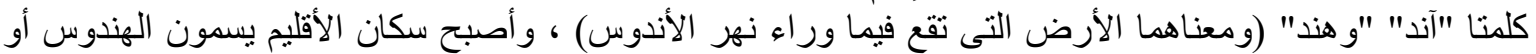

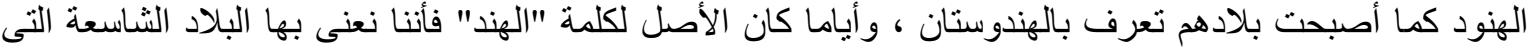

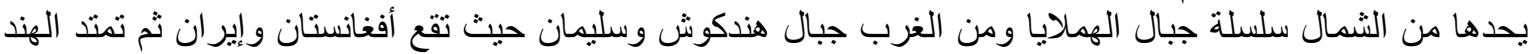

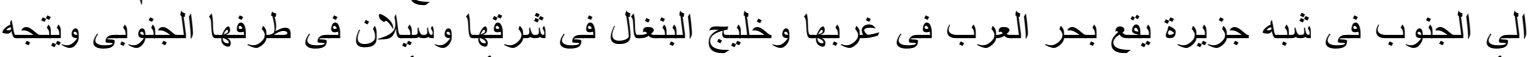

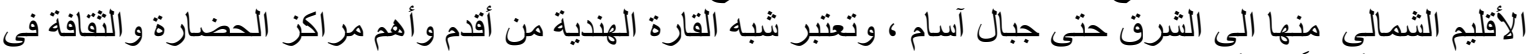

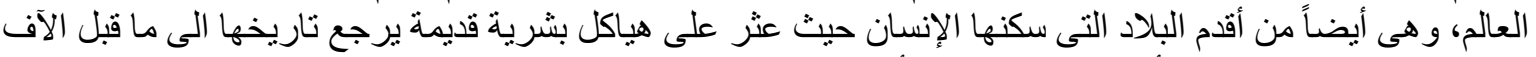

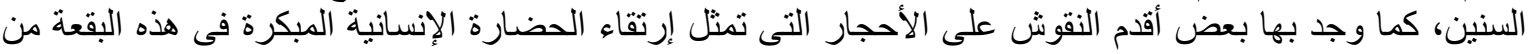

ـ المقريزى " تقي الدين أحمد بن علي " : المواعظ و الإعتبار في ذكر الخطط و الآثار ( الخطط المقريزية ) ، تحقيق

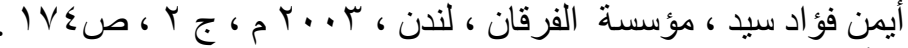

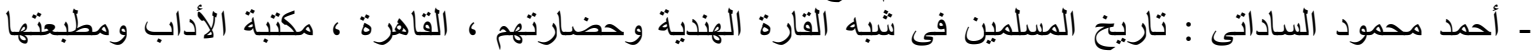

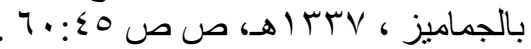

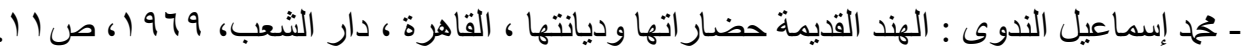

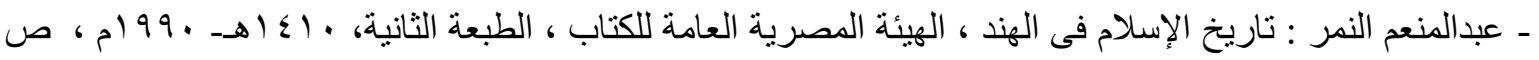
ص ص: $9: 1$

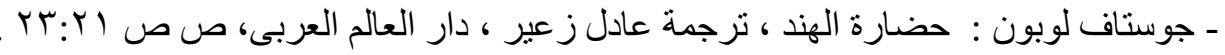

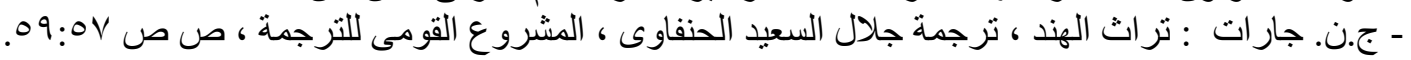

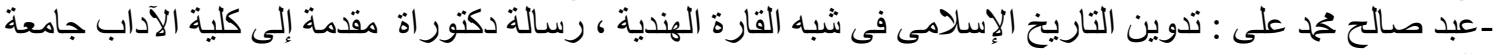

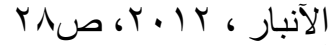

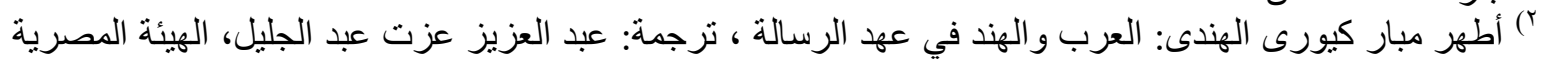

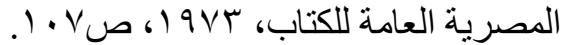

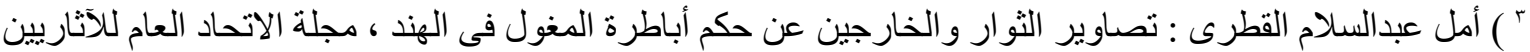

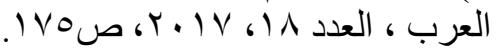

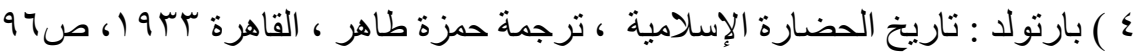
$\left.{ }^{5}\right)$ K.D. Bhargava. GUIDE TO THE RECORDS IN THE NATIONAL ARCHIVES OF INDIA. Part1: Introductory. New Delhi: 1950. PP. 7-18.

" ) حياة محمد البسام : النفوز البريطانى فى الخليج العربى وموقف الدولة العثمانية منه ، مجلة المؤرخ المصرى ، عدد $11 \leqslant 0$ (1990، 10

$\left.{ }^{7}\right)$ William Foster ,Englands, Quest of Eastern Trade ,London 1933,p46

$\left.{ }^{8}\right)$ Ramkrishna mukherjee,The rise and fall of the East India company London 1993,p69,

9) V.A Smith: The oxford history of india ,Karachi,oxford university press,1988,p228

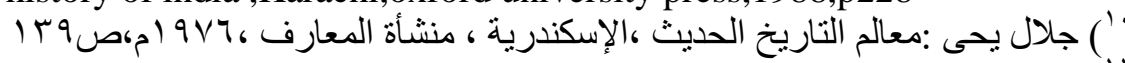

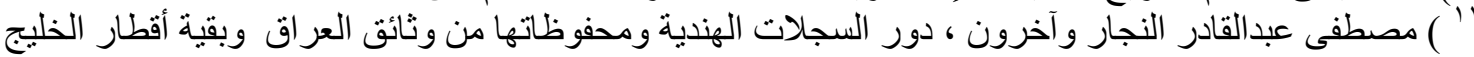

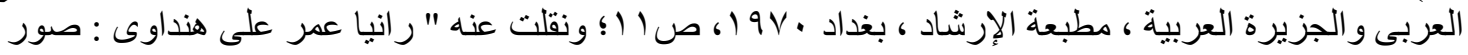

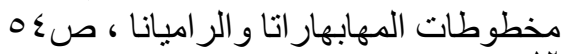

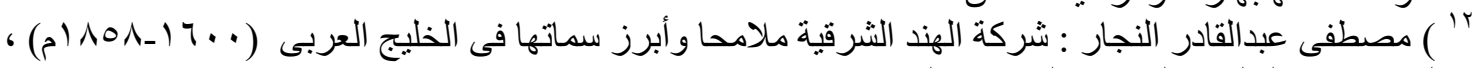
13) Philip Lawson, The East India company ,london1993,p27

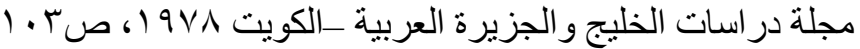
14) Y.M.E. Yapp. “The Establishment of the East India Company Residency at Baghdad, 1708-1806.” BULLETIN OF THE SCHOOL OF ORIENTAL AND AFRICAN STUDIES. University of London: Vol. XXX Part 2, 1967. PP. 324-336.

MarQuis cruzon ,British government In India ,Vol 1, London ,p27 وكذلك أنظر :-

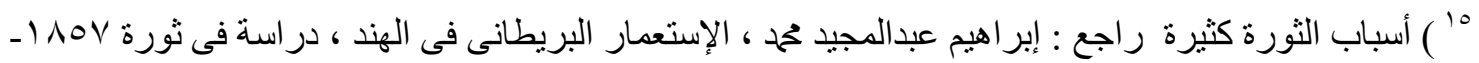

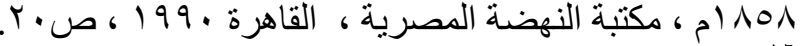

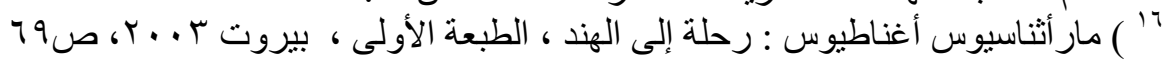


${ }^{17}$ ) Aditi ,Govil,The Mughal Court Of Europe ,A study Of It's Cultural and Comperical Policy Responses,ph.d, ,AliGrah Muslim University,2008,p148

18 ) Pramod Kumar Songer ,Growth of English Trade under The Great Mughal , ph.d,Panjab university,1985,p71

19 ) Pramod Kumar Songer ,Growth of English Trade under The Great Mughal ,p90

$\left.{ }^{20}\right)$ Stanley Lane pool,the coins of the Monghul Emperors of Hindustan In the British Museum ,London 1892,p Xcv

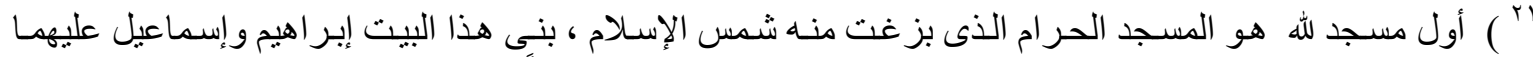

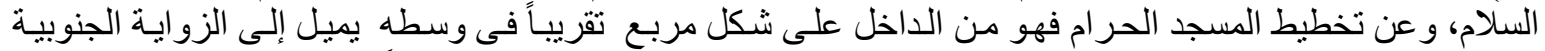

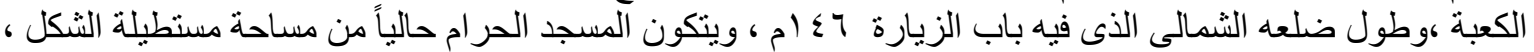

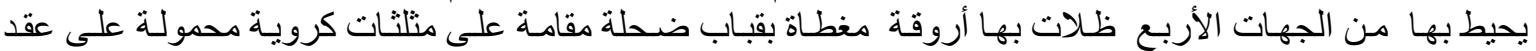

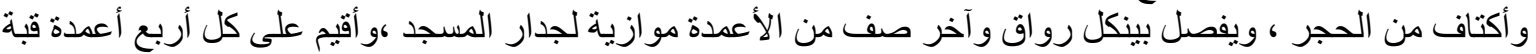

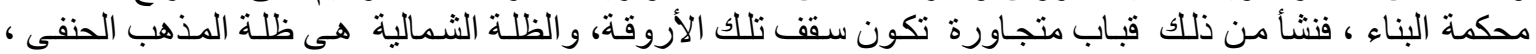

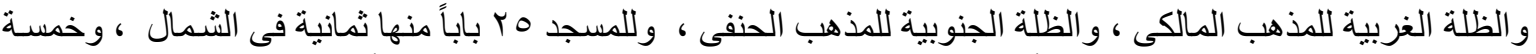

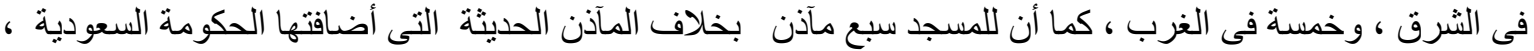

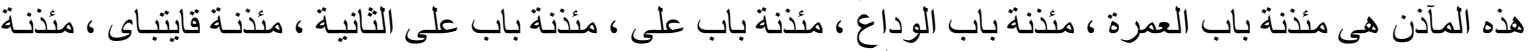

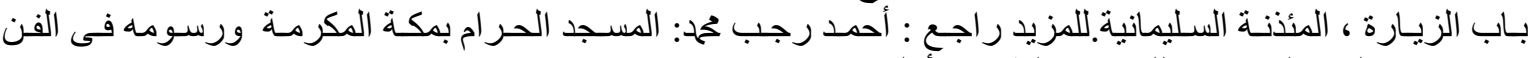

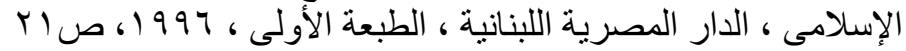

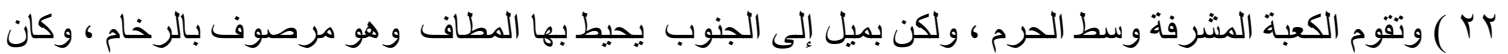

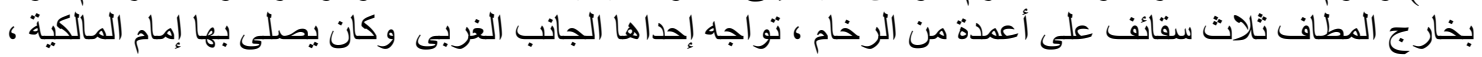

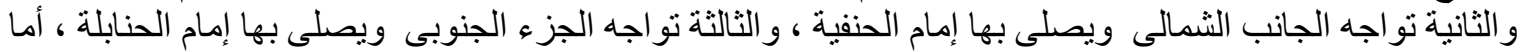

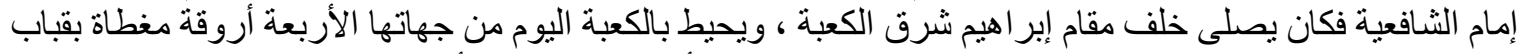

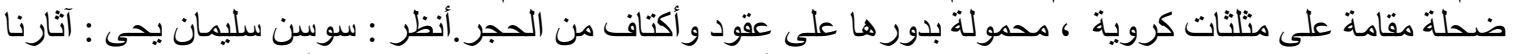

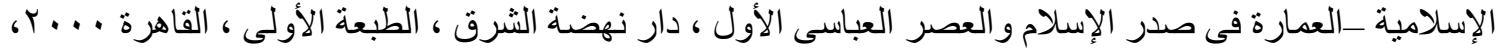
صنr

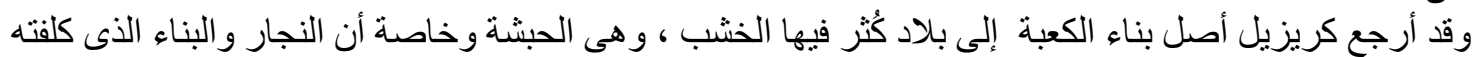

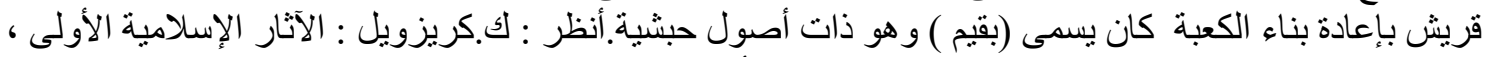

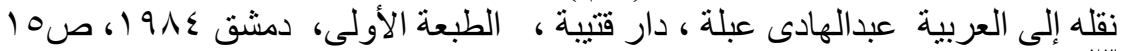

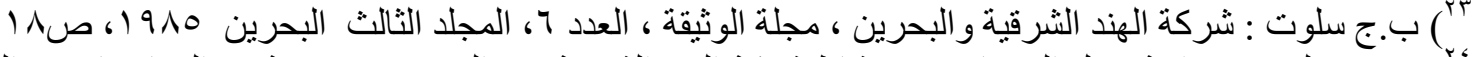

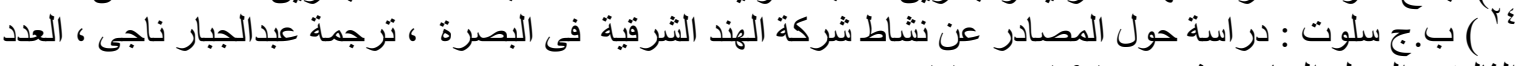

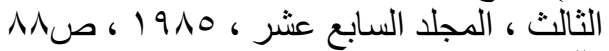

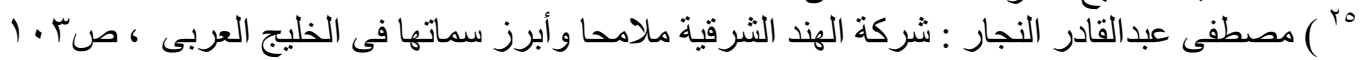
$\left.{ }^{26}\right)$ I.O.R.L G/29. "Missions of the British Government and the Government of India to the Court of Persia and the Pasha of Baghdad, 1798-1822 